\title{
A Randomised Comparative Study of Early Versus Delayed Laproscopic Cholecystectomy in Acute Cholecystitis
}

\author{
Gopal Sharma ${ }^{1}$, Mubashir Akram², Barinder Kumar ${ }^{3}$ \\ ${ }^{1}$ Assistant Professor, Department of Surgery, GMC, Rajouri, ${ }^{2}$ Consultant Surgeon, Department of Health, UT of J\&K, ${ }^{3}$ Assistant \\ Professor, Department of Surgery, GMC, Rajouri, India
}

Corresponding author: Dr Gopal Sharma, Assistant Professor, Department of Surgery, GMC, Rajouri, India

DOI: http://dx.doi.org/10.21276/ijcmsr.2020.5.2.16

How to cite this article: Gopal Sharma, Mubashir Akram, Barinder Kumar. A Randomised comparative study of early versus delayed laproscopic cholecystectomy in acute cholecystitis. International Journal of Contemporary Medicine Surgery and Radiology. 2020;5(2):B69-B71.

\section{A B S T R A C T}

Introduction: Still in present era there is dilemma of early laparoscopic cholecystectomy for acute cholecystitis with cholelithiasis. The present prospective study was done with an aim to evaluate the safety and feasibility of early Laproscopic cholecystectomy for acute cholecystitis and to compare the results with delayed Laproscopic cholecystectomy.

Material and Methods: In present prospective study 50 patients of acute cholecystitis were divided randomly to early laproscopic cholecystectomy group, (LC within $72 \mathrm{hrs}$ of admission), and delayed group, (initial conservative treatment followed by delayed laproscopic cholecystectomy, 4 weeks later). Data of duration of surgery, conversion to open surgery, duration of hospital stay and complications was analysed.

Results: Patients age varied from 8 to 75 years. The mean age of patients in group A was $42.25 \pm 10.20$ whereas mean age in group B was $44.60 \pm 8.50$ years. The mean duration of surgery in group A was $56.26 \pm 7.40$ minutes and in group B it was $54.30 \pm 6.30$ minutes. Duration of hospital stay was $5.10 \pm 2.15$ in group A whereas it was $9.80 \pm 2.20$ in group B which was statistically significant. ( $P$ value<0.05). Minor complications were noticed postoperatively in both the groups which were managed conservatively and were not statistically significant.

Conclusion: Early laproscopic cholecystectomy appears as safe and effective as delayed laproscopic cholecystectomy for acute cholecystitis within $72 \mathrm{hrs}$ from presentation and may shorten the total hospital stay.

Keywords: Acute Cholecystitis, Laparoscopic Cholecystectomy, Duration of Hospital Stay.

\section{INTRODUCTION}

Elective laparoscopic cholecystectomy has become the gold standard for treatment of symptomatic gallstones. ${ }^{1}$ In early days of laproscopy acute attack of cholecystitis was considered a relative contradiction for laproscopic surgery as patients were managed conservatively and discharged and then again re-admitted after 4 to 6 weeks for elective laproscopic cholecystectomy. ${ }^{2,3}$ Initially the surgeons were bit apprehensive of performing laproscopic cholecystectomy in acute attacks because in that case callots anatomy is distorted and not clear ${ }^{4}$, gall bladder is distended, oedamatous, adhesions are present with adjoining structures and tissues are friable with hypervascularity and congestion. Present era surgeons started performing laparoscopic cholecystectomy even in acute cholecystitis because of improved surgical skills, better knowledge of hepato-biliary anatomy and better visualization because of new generation cameras and optics. In fact Laproscopic cholecystectomy has now become the procedure of choice for patient presenting with acute cholecystitis unless it is contraindicated for technical reason or safety. Early laproscopic cholecystectomy if done in acute cases is associated with early recovery and shorter hospital stay however it is sometimes associated with high conversion rate and serious complications. ${ }^{5,6}$ The present study was done to evaluate the safety and feasibility of early laparoscopic cholecystectomy and compare the results with those of delayed laproscopic cholecystectomy in cases of acute cholecystitis with cholelithiasis.

\section{MATERIAL AND METHODS}

The present study was done in department of surgery GMC Rajouri from 1feb 2019 to 31januarys 2020. Fifty patients of acute calcular cholecystitis who were admitted in surgery unit 2 in emergencies or OPD were divided into two groups. Patients were diagnosed as a case of acute cholecystitis on the basis of history, clinical examination, and ultrasonographicaly (positive sonographic Murphy's sign, distended gallbladder, gallstones, thickened > $4 \mathrm{~m}$, edematous gallbladder and pericholecystic fluid). Patients were randomized into two groups depending upon whether the patient registration number was odd or even. In group A early laproscopic cholecystectomy within 72 hours was done while in group $B$ that was initially treated with broad-spectrum intravenous antibiotics and fluid resuscitation and then discharged, cholecystectomy was done at least 4 weeks after the 
initial admission. The patients were taken for surgery after obtaining informed consent. No patient selection was used for the surgical procedures. All the operations were carried out under general anesthesia.

\section{Exclusion criteria}

Patients with choledocholithiasis, previous upper abdominal surgery, acute pancreatitis or patients who were not fit for general anaesthesia because of their concomitant medical problems were excluded from the study.

The surgery was done under general anesthesia. Pneumoperitoneum was created by direct trocar insertion method through a supraumbilical incision. Standard Four laparoscopic ports were used. A $10-\mathrm{mm}$ supraumbilical port was used for camera, 10-mm subxiphoidal for working instruments, $5-\mathrm{mm}$ right subcostal along the midclavicular line and $5 \mathrm{~mm}$ on the right flank port for retraction. Calot anatomy is delineated first. If the gallbladder was overdistended that it was not possible to grasp it was emptied suction to allow better grasping. Dissection was done at cystic pedicle to isolate the cystic duct and the artery separately. Both were then clipped with liga clip and divided. Once the cystic artery and duct is ligated, gallbladder was dissected of its bed with a monopolar electrosurgical hook achieving complete haemostasis. After the gallbladder was separted from liver bed gallbladder was extracted through the subxiphoidal incision, which was enlarged if required. Hemostasis was achieved in the gallbladder bed, saline lavage was given if there was bile spillage till the colour of fluid was clear and suction drain was placed if clinically indicated. Port site incisions were closed with silk number- 1.Conversion to open surgery was performed through a right subcostal incision when required.

The parameters which were studied included patient's demographics, duration of surgery, intra- or postoperative complications and the length of hospital stay. For the delayed group, hospitalization duration was considered as total length of stay for both first and second hospitalizations added together.

\section{RESULTS}

Fifty patients of acute calcular cholecystitis who were admitted in surgery unit 2 in emergency or OPD of GMC rajouri from 1 Feb 2019 to 31 january 2020 were included in the study. All the patients were assigned randomily into two groups of twenty five patients each. In group A early laproscopic cholecystectomy within 72 hours was done while in the group B delayed laproscopic cholecystectomy was done. Following parameters were recorded.

There was no significant difference in terms of demography, age, sex, laboratory parameters, and ultrasonographic findings. There was no patient in delayed group in which there was failure of conservative treatment which required readmission and urgent surgery. Patients were operated under general anaesthesia in both the groups. The age of the patients varied from 8 to 75 years. The mean age of patients in group A was $42.25 \pm 10.20$ whereas mean age in group B was $44.60 \pm 8.50$ years. The mean duration of surgery in Group A was 56.26 \pm 7.40 minutes and in Group B it was 54.30 \pm 6.30 minutes. Three patients in Group A required conversion to open surgery. Out of three conversions one had bleeding from posterior vessel while callots anatomy was not clear in two patients in whom conversion to open was done. In Group B two patients required conversion to open because of dense adhesions at callots triangle. Duration of hospital stay was $5.10 \pm 2.15$ in Group A whereas it was 9.80 \pm 2.20 in Group B which was statistically significant $(\mathrm{P}$ value $<0.05)$. Minor complications were noticed postoperatively in both the groups which were managed conservatively and were not statistically significant (table-1).

\section{DISCUSSION}

500,000 people undergo cholecystectomy all over the world every year. The first Laparoscopic cholecystectomy was first done in the year 1987 and within no time it became gold standard for the treatment of symptomatic gallstones because of its vast advantages. But laproscopic cholecystectomy did not gain much importance in cases of acute cholecystitis as its role in such settings is still controversial. ${ }^{7}$ In past acute cholecystitis was considered a relative contraindication to laproscopic cholecystectomy the reason being that the surgeons were not well versed with hepato-biliary anatomy and instruments were not so good. Some studies ${ }^{8,9}$ done in recent past have shown that laproscopic cholecystectomy is safe and feasible procedure although with variable rates of complications and conversion. Keeping in view the above facts more and more studies are required for conclusive results.

The mean age of patients in group A was $42.25 \pm 10.20$ whereas mean age in group B was $44.60 \pm 8.50$ years. Similarly a study done by Chhajed $\mathrm{R}$ et $\mathrm{al}^{10}$ showed mean age of 44.2 $( \pm 11.4)$ in early laproscopic cholecystectomy and mean age of $39.5( \pm 11.7)$ in delayed group. The mean duration of surgery in group A was 56.26 \pm 7.40 minutes and in group B it was $54.30 \pm 6.30$ minutes. Similarly the mean operation time was $69.4 \mathrm{~min}$ in early group and $66.4 \mathrm{~min}$ in delayed group in a study done by Agarwal $\mathrm{R}$ et al. ${ }^{11}$ Another study done by Arafa $\mathrm{S} \mathrm{A}$ et $\mathrm{al}^{12}$ showed the mean operating time of 126.55 $\min$ (range, 50-210 $\mathrm{min}$ ) in the early group and $109.94 \mathrm{~min}$

\begin{tabular}{|l|c|c|c|}
\hline & Group A & Group B & P value \\
\hline Mean Age (years) & $42.25 \pm 10.20$ & $44.60 \pm 8.50$ & \\
\hline Mean duration of surgery (minutes) & $56.26 \pm 7.40$ & $54.30 \pm 6.30$ & \\
\hline Conversion to open surgery & 3 & 2 & $<.80 \pm 2.20$ \\
\hline Duration of hospital stay (days) & $5.10 \pm 2.15$ & Table-1: Showing various parameters studied. & \\
\hline \multicolumn{2}{|r|}{} \\
\hline
\end{tabular}


(range, 40-190 $\mathrm{min}$ ) in the delayed group. The difference in operation time in both the groups was not statistically significant. Duration of hospital stay was $5.10 \pm 2.15$ in group A whereas it was $9.80 \pm 2.20$ in group B which was statistically significant. (P value $<0.05$ ). Similarly a study done by Rouf $G$ et $\mathrm{al}^{13}$ showed hospital stay of 4.77 days in early group and 10.10 days in delayed group. Another study done by Kolla $\mathrm{S} B$ et $\mathrm{al}^{1}$ showed mean hospital stay of 4.1 days in early group and 10.10 in delayed group. Conversion rates in our study was similar in both groups which is in contrast to other studies done in past which showed higher conversion rates of early laproscopic cholecystectomy.

\section{CONCLUSION}

Early laparoscopic cholecystectomy when performed within 72 hours for acute cholecystitis is safe and feasible, with added advantage of a shorter hospital stay.

\section{REFERENCES}

1. Kolla SB, Aggarwal S, Kumar A, Kumar R, Chumber $\mathrm{S}$, Parshad R, et al. Early versus delayed laparoscopic cholecystectomy for acute cholecystitis: a prospective randomized trial. Surg Endosc. 2004;18(9):1323-1327.

2. Macafee DAL, Humes DJ, Bouliotis G, Beckingham IJ, Whynes DK, Lobo D. Prospective randomized trial using cost-utility analysis of early versus delayed laparoscopic cholecystectomy for acute gallbladder disease. Br J Surg. 2009;96(9):1031-1040.

3. Cuschieri A. Approach to the treatment of acute cholecystitis: open surgical, laparoscopic or endoscopic? Endoscopy. 1993;25(6):397-398.

4. A.P.Nagle,N.J.Soper, and J.R.Hines, "Cholecystectomy (open and laproscopy)," in Maingot's: Abdominal Operations, M. J. Zinner and S. W. Asmhley, Eds., pp. 847-861, McGraw-Hill, New York, NY, USA, 11th edition, 2007.

5. C. K. Kum, P. M. Y. Goh, J. R. Isaac, Y. Tekant, and S. S. Ngoi. Laparoscopic cholecystectomy for acute cholecystitis. British Journal of Surgery 1994;81(3):1651-1654.

6. R. G. Wilson, I. M. C. Macintyre, S. J. Nixon, J. H. Saunders, J. S. Varma, and P. M. King. Laparoscopic cholecystectomy as a safe and effective treatment for severe acute cholecystitis. British Medical Journal 1992;305(6):394-396.

7. Yamashita Y, Takada T, Kawarada Y, Nimura Y, Hirota M, Miura F, et al. Surgical treatment of patients with acute cholecystitis: Tokyo Guidelines. J Hepatobiliary Pancreat Surg 2007;14(1):91-97.

8. R. Sinha and N. Sharma. Acute cholecystitis and laparoscopic cholecystectomy. JSLS: Journal of the Society of Laparoendoscopic Surgeons/Society of Laparoendoscopic Surgeons 2002;6(5):65-68.

9. C.-M.Lo, C.-L.Liu, E. C.S.Lai, S.-T.Fan, and J.Wong. Early versus delayed laparoscopic cholecystectomy for treatment of acute cholecystitis. Annals of Surgery 1996;223(2):37-42.

10. Chhajed R, Dumbre R, Fernandes A, Phalgune D. Early versus delayed laparoscopic cholecystectomy for acute cholecystitis: a comparative study. Int Surg J
2018;5(4):3381-5.

11. Rati Agrawal, K. C. Sood, and Bhupender Agarwal Evaluation of Early versus Delayed Laparoscopic Cholecystectomy in Acute Cholecystitis. Surg Res Pract. 2015;23(1):34-40.

12. Arafa AS,KhairyMM, Amin MF. Emergency versus delayed laproscopic cholecystectomy for acute cholecystetis. Egypt J Surg 2019;38(3):171-9.

13. Rouf Gul RA, Sheikh RA, Salroo NA, Matoo AR, Wani SH. Comparison of early and delayed laparoscopic cholecystectomy for acute cholecystitis: experience from a single center. North Am J Med Sci. 2013;5(6):41

Source of Support: Nil; Conflict of Interest: None

Submitted: 03-04-2020; Accepted: 06-05-2020; Published online: 09-06-2020 